\title{
Philosophical Foundations for Complementary Protection
}

\author{
Matthew Lister ${ }^{I}$
}

A significant percentage of the people outside their country of citizenship or residence who are unable to meet their basic needs on their own, and need international protection, do not fall under the definition set out in the UN Refugee Convention. This has led many - both academic commentators and activists - to call for a new, expanded refugee definition, preferably backed up by a new, binding, international convention. In earlier work, I have resisted this call, arguing that there is good reason to pick out a sub-set of those in need of international aid - a set that largely, if not completely, corresponds to those picked out by the Refugee Convention - for special benefit and protection. However, even if Convention refugees are in some ways special, we are left with the question of what, if anything, is owed to those in need of aid who are not Convention refugees. In this chapter, I set out philosophical foundations for so-called complementary protection.

Following Jane McAdam, I take 'complementary protection' to be protection 'to persons falling outside the formal legal definition of "refugee", where this protection is seen as 'complementary to those assumed under the 195 I Refugee Convention (as supplemented by its I 967 Protocol)'. ${ }^{2}$ I will argue that while states which are able to provide such protection at reasonable cost have an obligation to do so, the different sorts of threats faced by those in need of complementary protection will typically justify providing a different sort and a different degree of protection than that provided to Convention refugees, at least in usual cases. I will explain why and how complementary protection may differ from

\footnotetext{
I Thanks to Luara Feraccioli, Michael Sevel, Kevin Walton, Patrick Emerton, David Tan, Jayani Nadarajalingam, Suzy Killmister, Maria O'Sullivan, and, especially, Christine Straehle and David Miller for helpful comments on earlier versions of this chapter.

2 J. McAdam, Complementary Protection in International Refugee Law (Cambridge: Cambridge University Press, 2007), pp. 2-3.
} 
refugee protection, ${ }^{3}$ and the limiting cases when the protection offered must converge.

\section{What Is Complementary Protection, and Why Is It Needed?}

As used in this chapter, 'complementary protection' is international protection provided by a state to a non-citizen who is outside her or his country of citizenship or habitual residence ${ }^{4}$ who is not covered by the UN Refugee Convention. ${ }^{5}$ This protection therefore potentially covers people fleeing from natural disasters ${ }^{6}$ and environmental degradation (such as drought); many people fleeing from international or civil wars; people fleeing from generalized violence, perhaps, but not necessarily relating to societal breakdown; and some people fleeing crime. Importantly, complementary protection is appropriate in these cases when the need to flee is not caused by persecution on the basis of a protected ground recognized under the Refugee Convention (race, religion, nationality, membership in a particular social group, or political opinion). Any of the above situations is one where persecution on the basis of a protected ground is possible, and if it exists, then we have a straightforward case for refugee protection.

Many people in situations like the above will not, however, be fleeing persecution on the basis of a protected ground. This can be because the danger is from a natural process such as a hurricane or volcano, or because the danger is directed at everyone in an area merely because they are in the area, and not because the person in question has a protected trait. Finally, the danger might be directed at the person in question individually, such as

3 In this chapter I will typically use the term 'refugee' to mean people falling under the UN Refugee Convention definition of a refugee unless otherwise noted. I do this not to attempt to solve normative questions by definition, but for the sake of terminological ease and consistency.

4 After this point, I will use 'county of citizenship' to mean 'country of citizenship or habitual residence'.

5 I will not here give any significant space to protection provided under the Convention Against Torture (CAT). This is not because the CAT is unimportant - it often is in practice, because of its unconditional prohibition on non-refoulement, allowing at least minimal protection for people who would otherwise be excluded under the Refugee Convention or complementary protection on various exclusion grounds, and is important theoretically in setting an absolute limit on state discretion on immigration controls. However, as most who qualify for protection under the CAT would also qualify for protection either under the Refugee Convention or under complementary protection if no exclusion ground applies, I will largely leave this issue aside.

${ }^{6}$ I have argued that people fleeing certain natural disasters - ones reasonably expected to be long-term or open-ended, where internal relocation is not a viable option - should be given the same treatment as Convention refugees, given that they meet what I take to be the logic of the Refugee Convention. See M. Lister, 'Climate Change Refugees', Critical Review of International Social and Political Philosophy, I7 (2014), 6I8-34. I maintain this position, but will here consider primarily natural or environmental disasters of a more limited sort. 
when criminals or gangs in a weak or failed state target business owners or more prosperous members, but not because the person in question has a protected trait.

The common element for complementary protection, then, is being in need of international protection, while being outside one's country of citizenship, where the danger that necessitated the flight is not connected with persecution on the basis of a protected ground. The lack of persecution is primarily what distinguishes these cases from cases of refugee protection. Before going on to explain the importance of this difference, I will explain why we should think of complementary protection, as discussed in this chapter, as applying only to people outside their country of citizenship, and not to all people in need of aid, regardless of their location. The answer to this question is related to the type of aid provided by complementary protection. As will be discussed in more detail later, the basic remedy provided by complementary protection is the ability to enter into and remain in a safe country for a set period of time. (How the period of time changes - and may, at the limit, become indefinite or permanent in different circumstances is a topic for later in the chapter.)

Aid given to people in need while they remain inside their country is not, therefore, complementary protection in the sense discussed here. Because providing aid to people in situations of the sort noted above while they remain inside their country has different predictable costs, it has a different normative structure. In some cases, aid in place may be cheaper, at least in the long run, than providing complementary protection. This is arguably so in the case of natural disasters that are serious in the short term but that do not present ongoing threats. ${ }^{7}$ Such situations do present significant difficulties in determining which states should bear the cost of providing aid, a problem eliminated, or at least ameliorated in the first instance, when people in need of aid present themselves at the frontier. In other scenarios, providing aid in place may be of such difficulty or cost that it is unclear that requiring it can justified. Intervention into many civil or international wars will often fit this description, especially when we note that intervention is far from certain to improve the situation, as the ongoing conflict in Syria shows.

Aid given to people who either are already in a safe country or arrive at a frontier is different. It is easy to assign first responsibility (even if effective burden-sharing remains a goal for the future), and the amount of risk one

\footnotetext{
7 When we consider that most people do not typically wish to leave their homes, the desirability of providing aid in place when possible increases.
} 
must undertake to provide the aid is comparatively small. The level of aid that must be provided will clearly depend on the resources of the host country in question (it would not make sense to expect or require Uganda to provide the level of aid that Germany can), and there may be upper limits to the amount of aid that can be required (to rule out the largely theoretical spectre of a society being 'swamped'), but because the sort of aid required by complementary protection is well suited to the situations where it is applied, it makes sense to apply it in those situations.

\section{How Does (or Should) Complementary Protection Differ from Refugee Protection?}

Having described the basic nature of complementary protection above, we may now ask how it differs (or should differ) from protection for Convention refugees. That there should be any difference is a contested issue. Jane McAdam, the leading expert on complementary protection, has argued that 'a legal status equivalent to that accorded by the Refugee Convention ought to apply to all persons protected by the extended principle of nonrefoulement' and that 'there is no legal justification for differentiating between the status of Convention refugees and the status of beneficiaries of complementary protection'. ${ }^{8}$ I will argue that there is good moral reason to distinguish between refugees, narrowly understood, and those owed complementary protection. This moral difference is in turn able to ground a justification for different legal treatment as well.

Differential treatment for those granted complementary protection and those granted refugee protection would potentially be justified if there were normally or usually predictable differences between the groups. My account of what is special about refugees provides a basis for such a difference. As I have elsewhere noted, in the case of people who are persecuted on the basis of a protected ground, we have good reason to think, first, that the danger that the people face is not likely to be short term; second, that there is usually no way to end the danger to them other than by giving them a new permanent residence; and, finally, that alternatives to providing a new permanent residence are unlikely to be morally acceptable or cost-benefit justified. ${ }^{9}$

${ }^{8}$ McAdam, Complementary Protection, p. I.

9 On Convention refugees, see M. Lister, 'Who Are Refugees?', Law and Philosophy, 32 (2013), 645-7I. On people fleeing certain long-lasting natural events, not currently covered by the Refugee Convention, see Lister, 'Climate Change Refugees'. 
The case is different for those covered by complementary protection, as set out in this chapter. In these cases, we can typically expect that the danger faced by those protected in this way will be not of indefinite duration but of a significantly shorter period. We may also hope that the danger faced can be addressed by means of aid or intervention at acceptable moral and monetary costs by other states, facilitating a return home by those so protected. Because the rights those in need can claim are related in a close way to the nature of the danger they face, there is therefore good reason to provide a different set of rights to those granted complementary protection rather than refugee protection.

Some examples can help make the case clearer. Because I have elsewhere set out the argument that, in the case of those eligible for refugee protection under the Refugee Convention, ${ }^{\text {IO }}$ we cannot reasonably expect the danger faced to be short term (in the relevant sense), and so must provide a 'durable solution' - that is, a new state in which permanent residence and eventually full membership is available - I will not rehash those arguments here. I will argue that, in the case of people who do not fit under the Refugee Convention (or certain extensions that I have argued for), we can usually, or typically, expect that temporary protection will suffice. If this is so, and if what we owe people in need is connected with how we are best able to help them, then there is some justification for treating complementary protection as distinct from refugee protection, at least insofar as this difference of need persists, a point to which I will return.

This is not the only possible justification for treating complementary protection as distinct from refugee protection. Matthew Price, for example, has argued that asylum - refugee protection as applied to Convention refugees - is and should be normatively different from other sorts of aid to people in need in that it essentially involves a political rebuke to governments who engage in persecution. ${ }^{\text {II }}$ Furthermore, cases of government action that justify asylum, on Price's account, signify a breaking of the normative bond between the state and the person persecuted. ${ }^{\mathrm{I} 2}$ These two factors are missing in cases where complementary protection is needed. In these cases, we are often dealing with states that are unable to provide the protection needed, either in the short term or for a somewhat longer period. A state is not properly rebuked, Price argues, for being unable to

ro See Lister, 'Who Are Refugees?' and 'Climate Change Refugees'.

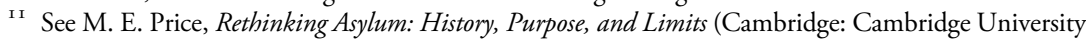
Press, 2009), p. I4. Price's 'political rebuke' account is unorthodox in rejecting the so-called nexus requirement for asylum, but this need not concern us here.

I2 Ibid., p. I67. 
protect its citizens. And, in these cases, the bond between the state and the citizen is not fundamentally ruptured in the way it is when the state persecutes its own citizens. When these factors are considered together, Price argues, we see that what is owed to people who qualify for complementary protection is temporary assistance, not the granting of a new nationality.

Jane McAdam, on the other hand, has insisted that 'there is no legal justification for distinguishing between the status of Convention refugees and beneficiaries of complementary protection'. ${ }^{13}$ Given this, McAdam argues, we should see the Refugee Convention not as picking out a special group of people in need of aid in a special way (as both Price and I have argued from different grounds), but as a lex specialis, which sets standards as a sort of example that ought to apply equally to all people in need of aid, regardless of the source of their need. ${ }^{\text {I4 }}$ If McAdam's claim is merely that there is no legal requirement found in international law that would compel treating Convention refugees and those who receive complementary protection differently, then she is arguably correct. ${ }^{\mathrm{IS}}$ But, insofar as her claim is that there is no good reason for different treatment, I will attempt to show it is mistaken. Furthermore, the moral differences, when joined with certain pragmatic considerations, provide good reason for not establishing a legal regime providing the same protections to those found to be Convention refugees and those in need of complementary protection, at least not in the first instance. (Limits to this claim will be discussed later.)

\section{Distinguishing Complementary Protection from Refugee Convention: Arguments from Political Morality}

Recall that on my account of refugees, those in need of refugee protection are picked out by the particular nature of their need - it is such that we can reasonably expect the need to be long-lasting, or at least of indefinite duration, and there is no good way to meet the need at acceptable cost and risk except by providing a new nationality to the people in need. I have argued that those covered by the Refugee Convention are paradigm

\footnotetext{
${ }^{13}$ McAdam, Complementary Protection, p. I I. $\quad{ }^{14}$ Ibid., p. I7.

is McAdam recognizes that states do not in fact typically give the same protection to Convention refugees as to others in need of aid, and that this difference is enshrined in many legal schemes providing some sort of complementary protection. McAdam, Complementary Protection, p. 4I. Given the role that state practice plays in determining international law, this is arguably relevant for the legal issue, placing tension on McAdam's strong claims about the law. However, on its own this is of only modest importance to the moral and political question addressed in this chapter.
} 
examples of such people, although at least some people displaced by environmental harms also clearly fit. On other accounts of refugee protection, such as Price's 'political rebuke' account, or Max Cherem's account ${ }^{16}$ focusing more specifically on persecution, people covered by the Refugee Convention are also picked out as especially in need of the sort of 'durable solution' provided for in refugee protection, particularly in countries such as the United States, Canada, and, in certain cases, Australia. ${ }^{17}$

Some examples can help illustrate why the case of those in need of complementary protection can typically be expected to be different from Convention refugee protection. I will offer several scenarios. Consider first people who must flee from one country to another because of a natural disaster which effects one part of their country, leaving other parts safe, but which makes it impossible or highly dangerous, in the short term, for the people fleeing either to remain in their home country or to flee to another part of their country. We might imagine people in a mountainous border region impacted by heavy rains leading to flooding, landslides, and impassable roads to safe regions in their own country, but having safe passage to a neighbouring country. In such a case, principles of complementary protection would call for admitting the people in need; providing them with short-term lodging, food, and other basic supplies; and helping them return either to their home region or to other safe regions in their home country when the immediate danger has passed. In a case like this, it is clear that there is no need to provide the sort of long-term protection and access to new membership called for by Convention refugee protection.

Other types of natural or environmental danger may be more widespread, impacting all or most of a state (the recent earthquakes in Haiti or Honduras after Hurricane Mitch might be good examples). Here the whole territory of the state is rendered unsafe, at least for a period, and people need longer protection, at least until aid can be provided incountry. Because the whole territory is impacted in cases like this, it is

${ }^{16}$ M. Cherem, 'Refugee Rights: Against Expanding the Definition of a "Refugee" and Unilateral Protection Elsewhere', Journal of Political Philosophy, 24 (2016), I83-205.

${ }^{17}$ The United States provides permanent resident status to refugees or asylees who have been in the United States for one year and who remain refugees (8 USC. $\$$ i I $59(b)$ ). Most people deemed 'protected persons' in Canada (a category in some ways broader than the Convention refugee definition) may apply for permanent resident status as soon as they are so designated. See www .canada.ca/en/immigration-refugees-citizenship/services/application/application-forms-guides/ guide-5205-applying-permanent-residence-within-canada-protected-persons-convention-refugees. html\# 5205 E2. In Australia, those who meet the refugee definition are eligible for 'permanent' visas at the time of the decision. For discussion, see J. Vrachnas et al., Migration and Refugee Law: Principles and Practice in Australia, 3rd ed. (Cambridge: Cambridge University Press, 2012), pp. I 82-86. 
less plausible to facilitate return to a safe part of the country. However, even in severe cases, such as that with Hurricane Mitch in Honduras, with the implementation of direct aid to the countries, they may become safe enough within a predictable time frame so as to justify making complementary protection presumptively temporary. ${ }^{{ }^{8}}$ In many cases like this, if people are required to return, even if aid is provided, they will return to a country facing significant difficulty and probably lower standards of living. However, as what is owed to those seeking complementary protection is not any particular standard of living, but only a reasonably safe place to live, then the presumptive ability of the state in question to return to minimally acceptable standards, at least with outside aid, in foreseeable periods of time, again helps show why complementary protection may be presumptively temporary, as opposed to Convention refugee protection.

Next consider countries faced with war, either international war or civil war. In such cases, people may be cut off from safe parts of the state, if they exist, necessitating flight into a neighbouring state. Or the whole state may be unsafe, making anyone who flees a potential beneficiary of complementary protection. The ongoing struggle in Syria is a clear example, but fighting in the Balkans, in the Caucuses, in Central Africa, and other countries provide all-too-numerous examples. In the case of any war, it is hard to know how long it will last, and so of course it would be foolish to assume that only relatively short-term protection would be needed. However, it is not unusual for wars to last a relatively short time. ${ }^{\text {I9 }}$ This again gives some good reason for the presumptive protection provided by complementary protection to be limited in duration, unlike Convention refugee protection.

Finally, consider people who flee from generalized societal breakdown or widespread criminal activity that is beyond the power of the government to control. Somalia, Libya, and several Central American states might here provide us with examples. These cases are perhaps the hardest to fit into my model, as we have limited experience with reviving failed states or bringing such widespread criminality under control. Perhaps these cases might fit with the more extreme cases of environmental or natural

${ }^{18}$ In fact, in the case of Honduras and Hurricane Mitch, Temporary Protected Status ('TPS') in the United States persisted for more than twenty years, to the current time, leading to significant controversy over its pending removal by the Trump administration. The situation in Honduras has been complicated by the rise of powerful criminal gangs, making this no longer a pure case. To my mind, the repeated extensions of TPS for Hondurans was likely itself a mistaken policy, but one that, when put in place, gave rise to new obligations, as discussed later.

I9 The wars in the Balkans, for example, lasted from ten days to a bit less than four years. 
disasters I have claimed should be seen as fitting into the logic of the Refugee Convention. Even here, however, we might rather take a more conservative approach, hoping to use outside aid to restore the countries to sufficient stability (as doing so is somewhat less likely to be unduly costly than is intervention into a functioning society), and hold that presumptively temporary protection of the sort provided by complementary protection should be the first step.

At this point it is important to note two complications to my account so far, and show how they do not invalidate the general approach. First, we should note that, in each of the sorts of cases I have discussed above, it is possible that at least some of the people involved - perhaps a significant percentage of them - will in fact qualify as Convention refugees. This is because none of these scenarios, as described, is incompatible with people suffering, or having a well-founded fear of suffering, persecution on the basis of a protected ground. To take what is perhaps the easiest example, some people who have to flee from a civil war may have to flee not merely because they are civilians in the way of combatants, but because they are members of a disfavoured ethnic or religious group which would be singled out for maltreatment amounting to persecution by an approaching army. Environmental harms may also give rise to Convention refugees. If a disfavoured ethnic group lives in a remote area of the country, and is intentionally cut off from aid needed in response to the harm caused by natural disasters and prevented from safely relocating within the remaining unaffected areas within the country because of their ethnicity, then they are plausibly Convention refugees. In cases like this, we should provide Convention refugee status to anyone who warrants it, even if they could also be covered by complementary protection. As I will discuss in relation to mass flight/influxes later, we may have good pragmatic reasons for first applying complementary protection to everyone in question and only later screening people to see if they might qualify for Convention refugee protection, but these pragmatic reasons do not negate the obligation to provide Convention protection to those who warrant it. Therefore, the fact that some people who qualify for complementary protection on my account would also qualify for Convention refugee protection is no inherent problem. ${ }^{20}$

${ }^{20}$ We might worry that states, eager to avoid the greater duties that come with Convention refugee protection, will simply grant complementary protection to all people seeking aid and not proceed to see if any need or warrant Convention refugee protection. McAdam has noted reason to worry about such practices in relation to the EU Qualification Directive, a form of complementary protection. See McAdam, Complementary Protection, p. 5I. This is a real worry, but as the most 
The second potential complication to my account arises from the fact that, while I have said that those in need of Convention refugee protection 'typically' or 'usually' will need protection for an indefinitely long period of time, warranting granting them access to full membership and eventually citizenship, and that those in need of complementary protection 'typically' or 'most often' need only temporary protection, implying that they do not, at least at first, need access to full membership and citizenship, there will be many exceptions to this claim. ${ }^{2 \mathrm{I}}$ This is to say, some people who qualify under current law as Convention refugees would, in fact, be able to safely return to their homes within a tolerably short period of time, and some who qualify for complementary protection will not be able to safely return for significant enough periods of time that it will seem unreasonable to not grant them full membership. Does this tell against having policies of the form I have suggested?

I will address later how what is owed to those granted complementary protection should change over time, as periods of need grow, but the more basic point should be addressed first. Once we see that we are here trying to craft just policies, not engage in conceptual analysis or metaphysics, and see that policies are, by their nature, general, this difficulty loses much of its force. Policies must be crafted, at least in the first instance, for typical or usual cases. The existence of cases that do not fit well into the policy, by itself, does not undermine the basic correctness of the policy. ${ }^{22}$ What matters for crafting a policy is that it get the core cases correct without too many anomalies, and that there is a way to deal with anomalous cases. We find this both in the case of Convention refugees (where the 'cessation' clause allows for the ending of protection when the threat to the refugee is in fact short lived) and, at least potentially, in complementary protection, where threats that turn out to be long term can, and should, give rise to more permanent protection. Therefore, the fact that there are exceptions to the general claims about the type of protection needed under Convention refugee protection and complementary protection is not, on its own, a

likely alternative is not providing protection at all to those who qualify for complementary protection, I think it is a risk that must be taken.

${ }_{21}^{21}$ This is noted in McAdam, Complementary Protection, p. 92.

22 On this point, often missed by philosophers, see M. Dempsey and M. Lister, 'Applied Legal and Political Philosophy', in K. Lippert-Rasmussen, K. Brownlee and D. Coady (eds.), A Companion to Applied Philosophy (Oxford: Wiley Blackwell, 2017), pp. 315-19. In particular, the tendency of philosophers to treat what are best seen as anomalies as (philosophical) counter-examples is shown to be mistaken when we are considering policies, all of which are, of necessity, both over- and under-inclusive. 
problem for the account presented here, given that each approach gets the core or most typical cases correct.

\section{Distinguishing Complementary Protection from Refugee Convention: Pragmatic and Political Arguments}

There are also strong arguments for distinguishing complementary protection from Refugee Convention protection that are political or pragmatic in nature. If the great weight of the moral arguments told in favour of providing the same protection for all in need, these arguments would, perhaps, not be persuasive on their own, but, given that there are good moral reasons for the distinction, these more practical arguments can provide further weight. One reason sometimes given for having only one form of protection for those in need of international aid is the idea that this will ensure that a high level of protection is given to all who need it. The worry here seems to be that, if more than one level of protection is possible, states will tend to 'level down', providing only the lower level. ${ }^{23}$ While this is a legitimate worry, I think that it gets the nature of the risk wrong. Insofar as we retain Convention refugee protection as a distinct standard, we maintain that there is a higher standard th - nust morally and legally for parties to the Refugee Convention be me we move to create a new standard, one which encompasses both standard Refugee Convention protection and complementary protection, we are more likely to get the sort of levelling down feared than if we have two distinct standards, as there is no reason to think that the higher standard of Convention refugee protection would be applied to everyone in need of aid, and good reason to doubt this.

Similar arguments tell against the idea that we should attempt to craft a single, unified account of protection, one which covers all cases but perhaps provides protection on a sliding scale of need. ${ }^{24}$ Doing so would risk the possibility of lowering the level of protection to Convention refugees at least as much as raising the level owed to others in need of aid. While it is clear that the current Refugee Convention is far from perfect, ${ }^{25}$ it does provide the basis for strong protection to many in need of

${ }^{23}$ This worry is discussed by both Price and McAdam. See Price, Rethinking Asylum, p. I66, and McAdam, Complementary Protection, p. 5 I.

${ }^{24}$ For helpful discussion about the wisdom of attempting to institute a new refugee convention, see L. Ferracioli, 'The Appeal and Danger of a New Refugee Convention', Social Theory and Practice, 40 (2014), I 23-44.

25 See, e.g., the extension argued for in Lister, 'Climate Change Refugees'. 
aid. Reopening it for negotiation would risk this. On the other hand, addressing complementary protection on its own would rather provide another layer of protection to the total tool-kit, one which would supplement the Refugee Convention, the Convention Against Torture, and other regional and more basic human rights commitments.

\section{Functional Aspects of Complementary Protection}

In this section I will provide detail on the workings of complementary protection as justified above. I will look at the relationship between complementary protection and mass flight or influx, at how individualized' the harm feared must be, and at how complementary protection should be able to serve as both a shield from removal and a key for entry.

\section{Complementary Protection and Mass Flight/Influx}

Complementary protection is often associated with protection for people in the case of mass flight from danger or influx into a country. Given the examples listed above of paradigm cases where complementary protection is appropriate, this is no surprise. Natural or environmental disasters, civil war, and international war all often give rise to large-scale movements of people. Furthermore, we may think that large-scale movements of people call for and justify more streamlined procedures of the sort often associated with complementary protection. I contend, however, that the connection between complementary protection and mass flight is only superficial and pragmatic, not deep or fundamental. There are two reasons for this. First, as noted briefly before, it is not unusual for people involved in a mass flight or influx to be properly eligible for Convention refugee protection, at least when they are carefully evaluated. Revising the Refugee Convention to cover certain long-term environmental harms will make this even clearer. This shows that there is no necessary connection between mass flight/ influx and complementary protection.

Mass flight or influx, however, does tend to present difficulties for traditional Convention refugee protection procedures, insofar as those are highly individualized and semi-juridical in nature. These procedures are arguably appropriate when time and resources allow for them, given the weighty nature of the protection that is, or ought to be, associated with Convention refugee protection - membership in a new state. However, when large numbers of people arrive in a short time, such procedures are often highly unwieldy and cannot be properly applied - certainly not at 
acceptable costs. This suggests that there will often be grounds for providing a less individualized and less generous protection in the short term for those involved in mass flight or influx. This sort of immediate protection, provided to everyone who fits certain general characteristics, for a set period of time, can be seen as an application of complementary protection, even it is not the only form.

\section{How Individualized Should Complementary Protection Decision Be?}

This raises our next question - how individualized should complementary protection adjudication be? In the case of Convention refugee protection, decisions to grant protection are typically highly individualized, in that they involve particular applications, close inspection of claims, and a need to show that the applicant meets the relevant requirements of the Refugee Convention. These decisions are often undertaken in a judicial or semijudicial forum, and can require gathering substantial amounts of evidence. It is at least arguable that the very weighty remedy of granting access to new membership justifies this relatively onerous process. There is reason to doubt, however, that such process is justified in the case of complementary protection.

Persecution on the basis of a protected ground - a core aspect of traditional Convention refugee protection - involves an intentional targeting, at least to a degree, of particular individuals. ${ }^{26}$ It is at least not implausible that targets of persecution could and should be able to show that persecution is taking place on the basis of the protected ground, that they have a well-founded fear of the persecution, and that they have the trait in question, at least to the standard of proof properly required for refugee determination. As seen from our examples earlier, this sort of targeting is at least not required, and will often be uncommon, in situations justifying complementary protection. Environmental disasters do not care whom they harm, and even armies in wars often are not directly targeting civilians. Even if armies do target civilians, this is usually because of their location more than specific traits. While some dangers which may give rise to a claim for complementary protection, such as danger from criminals whom the government cannot control, may involve a degree of

\footnotetext{
${ }^{26}$ The targeting may be focused on the trait - the protected ground - rather than the specific individual who has it more personally, but it is still a distinct, important feature of the person who is targeted.
} 
targeting, we can see here that this is not a necessary feature in the same way that it is with Convention refugee protection.

Given the above factors, it is implausible to require the same sorts of individualized evidence and semi-juridical proceedings for complementary protection, even apart from the lesser degree of protection offered at first. It should usually suffice to show that the applicant has general features that make or would make him or her susceptible to the harm feared. For example, if the protection offered is due to a state-wide natural disaster affecting a whole country, what would need to be shown is that the person in question is a citizen of the country in question, and perhaps that he or she did not have the right to be in any other safe state. While these procedures would make dealing with mass flight or influx easier, they are also appropriate for other situations, such as when people already in a safe state are able to apply for leave to not return to a state where they would face appropriate danger. In the somewhat more rare case where complementary protection is applied to people who face some degree of targeting, but the situation does not fit within the Refugee Convention model (such as certain cases of fearing crime), more specific evidentiary showings may be appropriately required, but this follows easily from the fact that there will not be general criteria to appeal to. In the most common cases, however, both the nature of the threats that justify complementary protection and the lesser degree of aid initially offered suggest that less individualized and less juridical procedures are appropriate for determining when protection is due.

\section{Should Complementary Protection Be a Shield (from Removal) or a Key (to Enter)?}

One major difference between different currently existing forms of complementary protection is whether they provide a means for people outside a state to enter it to seek protection, or merely provide a shield from removal to people already in a state to a third state where danger would be likely. The EU's Qualification Directive is an example of a form of complementary protection that provides a key to entry. ${ }^{27} \mathrm{~A}$ person who warrants 'subsidiary protection' (the technical term for the type of complementary protection provided under the Qualification Directive) may appear at a border and invoke the law so as to not be turned away. On

27 Council Directive 2004/83/EC of 29 April 2004. For discussion of the Qualification Directive, see McAdam, Complementary Protection, pp. 53-I Io. 
the other hand, TPS in the United States functions only as a shield from removal for those already in the United States when the protection is granted, ${ }^{28}$ and provides no right to enter the United States for those not already in the country at the time the protection is ordered. TPS in the United States provides protection to a broader range of individuals than does the Qualification Directive, but limits this to those currently present, so as to avoid serving as a draw for those not already in the country. The question for this section is whether restricting complementary protection to serving only as a shield from removal for those already in a country, but not as a key to enter, is justified by the logic of complementary protection.

While the worry in the United States about its TPS program becoming an attractor for unwanted migration has some pragmatic force, limiting complementary protection to only those currently inside a safe country when the danger strikes would go against the normative logic of the idea. As has been noted above, one justification for states to provide protection inside themselves, whether Convention refugee protection or complementary protection, is that this can usually be done without grave risk to the state taking in those in need. Furthermore, insofar as the protection is supplied primarily to those who journey to the state - as opposed to the state going out on its own to provide the aid - the costs of providing the aid may be reduced. The later discussion of the normative foundations for providing complementary protection will further make clear that reducing it to only a shield against deportation, and not allowing it to be a key to enter, is normatively insufficient. Therefore, unlike the current US TPS program, complementary protection should provide a means for those in need of aid to enter a safe country. Of course, considerations of burden sharing may imply that the state of first entry need not be the state where even the sort of temporary protection appropriate for complementary protection must take place. But, except in the most extreme cases of emergency, decisions about which state should host those in need of complementary protection will need to be made after an initial grant of entry.

\section{Degrees of Protection, and Changing Protection over Time}

Recall that the point of complementary protection is to provide needed protection to people fleeing dangers other than those that would give rise to Convention refugee protection, and who cannot receive protection in

288 USC. $\$ \operatorname{I} 254 a(c)$ I(A)(i)-(ii). 
their home states. Once we recall the wide variety of dangers that might necessitate complementary protection, it becomes clear that not all dangers require the same sort or degree of protection. (This is one more contrast with Convention refugee protection since, as I have elsewhere noted, ${ }^{29}$ one of the defining features of Convention refugees is that, whatever the particular danger they face, they can typically be helped effectively only by being provided with a new state in which to have full membership.) Different sorts of protection may be appropriate, then, in responding to different sorts of threats.

When a threat is either plausibly expected to be short lived or where movement to a safe part of the home state is reasonably possible, then basic humanitarian aid will likely be all that is required. This would consist in providing shelter, food, immediate medical treatment, clothing, and similar things, but need not consist in more. Such basic levels of aid would be most plausible for people fleeing natural disasters (or, possibly, some very limited military engagements) which affect only a particular portion of a country or which could be addressed within a matter of weeks or, at most, months. Other threats, however, will predictably last longer. This might be because of a more significant natural disaster or environmental harm, or more widespread and significant fighting in a country. In cases like this, more aid will be needed, such as more secure housing and at least limited forms of social integration, such as access to education for children, more significant forms of health care (including at least ongoing maintenance care), and, if the period of protection extends beyond a few months, at least some degree of access to the labour market, including aid in finding work. When the need for aid stretches beyond a few months, but is still such that return seems plausible in a reasonably short period of time (such as a few years, at most), then full employment rights and normal education for children should be made available, as well as access to at least most forms of health care. ${ }^{30}$ Importantly, while these degrees of protection are presented as successive, there is no necessity that they (or other

29 Lister, 'Who Are Refugees?'. Price reaches a similar conclusion on the basis of his 'membership principle' and the associated 'political rebuke' theory of asylum. See Price, Rethinking Asylum, pp. I67-69. I explain why my more pragmatic protection-based approach is preferable to Price's in M. Lister, 'The Place of Persecution and Non-State Actors in Refugee Protection', in A. Sager (ed.), The Ethics and Politics of Immigration: Core Issues and Emerging Trends (London: Rowman and Littlefield, 2016), pp. 47-5I.

${ }^{30}$ It may be reasonable to place restrictions on access to healthcare, so as to keep the cost of helping those in need down. Truly elective procedures may be excluded, and less expensive options taken, such as providing eyeglasses rather than laser eye surgery. Pressing further into these details would require more details of healthcare policy than I am able to provide. 
intermediate steps) be followed in order. While basic humanitarian aid will often be the starting place in the case of mass flight or influx, once the nature of a situation is well grasped, it may make sense to simply apply the most plausible degree of protection for that situation, rather than marching through intermediate steps.

Unfortunately, it is not unusual for situations that could have required temporary protection to linger on for indefinitely long periods of time, either because the underlying problem has not or could not effectively be solved ${ }^{3 \mathrm{I}}$ or because further developments complicate the original problem, making return unsafe and implausible. ${ }^{32}$ Many current systems of complementary protection do not have ways to deal with such situations. ${ }^{33}$ For example, TPS, in the United States, explicitly prohibits those holding the status from gaining permanent resident status under most circumstances. ${ }^{34}$ There is good reason to reject such schemes and to insist on eventual access to full membership for those granted complementary protection for significantly extended periods. Two considerations are useful to look at here.

First, recall that the most important justification for granting Convention refugees full membership in a safe society was the reasonable expectation that they could not return to their home state within an acceptably short period of time. ${ }^{35}$ If that justifies granting new membership to Convention refugees, then it would seem to also justify granting full membership to those given complementary protection in situations where we have compelling reason to believe that they will not go home in an acceptable period of time. Having lived a number of years in the host society provides this knowledge. Second, there are more general reasons to

${ }^{\text {I }}$ A well-known natural disaster case is that of Montserrat, rendered largely uninhabitable by volcanic activity. When it became clear that the threat was unlikely to be temporary, the second Bush administration, rather than follow the path suggested here, simply revoked the TPS for citizens of Montserrat in the United States. While it is perhaps yet too early to say, we may worry that the civil war in Syria will continue for such a time and degree that an indefinite need for protection is plausible.

32 As noted above, the situation of people from Honduras with TPS in the United States after hurricane Mitch is perhaps like this, with a mixture of general economic problems and serious violence from dangerous criminal gangs contributing to this population having TPS in the United States for more than twenty years.

33 We may also ask what sorts of institutional structures are most likely to be able to implement an adequate system of administration and review here. I cannot hope to answer these difficult, largely practical, questions in this chapter, but see no intrinsic reason to think that well-crafted state-based institutions would be less likely to work than would international institutions, especially given the difficulties of agreeing on international rules and institutions with real bite.

348 USC. $\$ \$_{1254 a(f) ; 8}$ USC. $\$$ I $229 b(b)(\mathrm{r}) . \quad{ }^{35}$ Lister, 'Who Are Refugees?'. 
think that anyone who lives in a society for a significant period of time should have access to full membership. This is most clearly the case for migrants who are voluntarily admitted, but the reasoning can be extended beyond these cases. ${ }^{36}$ Therefore, if those granted complementary protection remain in the host country for extended periods of time, they ought to be granted access to full membership. ${ }^{37}$ While there may be some worry that such a requirement will encourage host states to end protection when it is still needed - we ought not take this lightly - we may also hope that this requirement will encourage states to help make home countries safe, by providing aid, development assistance, or security, thereby allowing those given complementary protection to return home safely in a relatively short period of time. Because the justification for different treatment for those owed complementary protection and Convention refugee protection is a difference in need, in cases where this difference in need can no longer be made out, the grounds for different types of protections lapse. When the normative difference between people owed complementary protection and those who warrant Convention refuge protection has lapsed, it is therefore appropriate to provide the same level of protection - access to full membership - to each. This will be a limiting case for complementary protection, as in many - probably most - cases, shorter term protection will suffice, while indefinite protection is the paradigm case for those owed Convention refugee protection.

\section{Why Provide Complementary Protection?}

The last two (related) questions are, in some ways, the most fundamental why should states grant complementary protection to those who need it, and why think they will or would do this? The two questions are related. If there is good reason to think that most states will not do what they ought to, then the obligations of other states may change in light of collective action problems and free-riding. So, if we want to argue that states should provide the protection described here, we need to show that it is at least not largely implausible that they would do it. While these questions are in some ways more fundamental than those above, the way that the normative question interacts with the practical one makes it necessary to first

\footnotetext{
${ }^{36}$ M. Lister, 'Citizenship, in the Immigration Context', Maryland Law Review, 70 (2010), 21 8-29; J. Carens, Immigrants and the Right to Stay (Cambridge, MA: MIT Press, 2010).

37 For helpful discussion of how the passage of time can change moral and legal rights and obligations, see E. Cohen, The Political Value of Time zenship, Duration, and Democratic Justice (Cambridge: Cambridge University Press, 2008)
} 
describe in some detail what complementary protection would consist in before showing if it is feasible and required.

The normative requirement to provide complementary protection has two grounds. The first stems from a general duty of states to provide aid to those in need. Several different grounds for such a duty have been proposed, including a 'Natural Duty of Justice', as argued for by Allen Buchanan, which grounds 'a limited moral obligation to help ensure that all persons have access to institutions that protect their basic rights' ${ }^{38}$ and a duty of humanitarianism, argued for by Matthew Gibney, ${ }^{39}$ among other approaches. These duties may be thought to be owed to other states, as the agents of their citizens, in the first instance, but in cases where a state cannot or will not provide protection, shifting the obligation to individuals in need is the required step. The second ground relates to the necessary conditions for granting states a right to control their own borders. We may hold that if states have a right to control their own borders, this is conditional on such a right not putting others in unacceptable conditions. The duty to accept refugees, I have argued, is one plausible constraint on this right. I have attempted to show, in this chapter, that providing complementary protection is a reasonable further requirement.

Finally, is it reasonable to expect states to be willing to provide this protection, given that it potentially creates a duty to provide aid to many millions of people? I claim that it is reasonable, for two reasons. First, as McAdam notes, many states already accept some degree of obligation to provide complementary protection. ${ }^{40}$ Given this, the duty set out here does not create a fully new right, but rather formalizes and clarifies duties already widely accepted. Second, the duty to provide complementary protection set out here could form the basis of a new multilateral agreement, similar in some ways to the Refugee Convention, which would help establish international norms and prevent collective action problems and free-riding. While an agreement cannot do this on its own, it may be an essential step toward this end.

${ }^{8}$ See A. Buchanan, Justice, Legitimacy, and Self-Determination: Moral Foundations for International Law (Oxford: Oxford University Press, 2004), p. 27. For helpful discussion of how such a natural duty of justice relates to questions of protecting human rights, see J. Mandle, Global Justice (Cambridge: Polity Press, 2006), pp. 46-48.

39 M. J. Gibney, The Ethics and Politics of Asylum: Liberal Democracy and the Response to Refugees (Cambridge: Cambridge University Press, 2004), pp. 230-33.

$4^{\circ}$ McAdam, Complementary Protection, p. 42. 
Of course, even if everything I have argued for in this chapter is accepted, many questions about complementary protection, both practical and theoretical, remain. I hope, however, to have shown the basic normative commitments that follow from a duty to provide complementary protection, how and why this type of protection differs from Convention refugee protection, and gone some way toward explaining why states might take on this burden. If this is so, then the case for complementary protection is now more clearly made. 